\title{
Pre-analysis plan \\ Price dispersion in the remittance industry: The role of fintech, comparison shopping, and other factors
}

\author{
Angelino Viceisza;, Spelman College and NBER \\ Daniel Xu† Duke University and NBER
}

March 3, 2021

\begin{abstract}
Remittances to developing countries surpassed US\$ 550 billion in 2019. Several micro-level studies have reported impacts of remittances on recipient households. So, there have been claims to reduce the price of sending money. Comparison websites, i.e., platforms like kayak.com but for sending money, have been proposed as a potential tool for reducing remittances prices; however, their impacts are likely to depend on the market failure in question. For example, if migrant consumers shop or search inefficiently, comparison websites are more likely to have an impact. On the other hand, if the market inefficiency is primarily driven by supply-side barriers such as the last-mile problem or regulation, comparison websites are less likely to have an impact. This project will assess whether comparison websites, and comparison shopping more generally, have the potential to impact the demand and supply sides of the remittance industry. In so doing, it will seek to describe consumer, firm, and industry characteristics that may moderate such impacts. The project will have three stages. The first stage, which is laid out in this version of the pre-analysis plan (PAP), will exploit existing data to do a first pass on the research questions. The second stage, which will be pre-registed as an updated version of this PAP, will collect primary data and additional secondary data to pin down causal factors. The final stage will incorporate findings from the first two stages to assess potential welfare impacts.
\end{abstract}

JEL Codes: C93, F22, F24, I3, L00, O12

Keywords: remittances, price dispersion, fintech, comparison shopping, price determinants, field experiments, structural modeling, welfare impacts

*aviceisz@spelman.edu

†daniel.xu@duke.edu 


\section{Motivation and research questions}

According to the Global Knowledge Partnership on Migration and Development (KNOMAD), remittances to developing countries surpassed US\$ 550 billion in 2019. Several micro-level studies have reported impacts of remittances on recipient households, for example, Brown (1994) and Finkelstein Shapiro and Mandelman (2016) on entrepreneurship, Adams (1998) on agricultural assets, Edwards and Ureta (2003) and Gyimah-Brempong and Asiedu (2015) on education, Osili (2007) on savings, Amuedo-Dorantes and Pozo (2011) on health, Alcaraz et al. (2012) on child labor, and Riley (2018) and Lee et al. (2021) on consumption. So, there have been claims to reduce the price of sending money. At the 2009 G8 summit in L'Aquila Italy, policymakers endorsed the objective of reducing the cost of remittance services by five percentage points in five years. As of the fourth quarter of 2020, the average price of sending US\$ 200 globally was 6.51 percent (KNOMAD's Remittance Prices Worldwide), compared to a target of three to five percent.

Comparison websites, i.e., platforms like kayak.com but for sending money, have been proposed as a potential tool for reducing remittances prices $]_{1}^{1}$ For example, it has been argued that the creation of publicly available databases containing detailed information on the cost of sending remittances is one of the most efficient means to improve the transparency of the market and thus, reduce prices. Perhaps this is not surprising given the impacts that comparison websites have had in other industries, e.g., Brown and Goolsbee (2002) for insurance and Scott Morton et al. (2015) for travel. At the same time, the impacts of comparison sites are likely to depend on the market failure in question. For example, if migrant consumers shop or search inefficiently due to limited financial literacy (e.g., Woodward and Hall, 2012) or asymmetric information about firms (e.g., Nishida and Remer, 2018; Luco, 2019), comparison websites are more likely to have an impact. However, if the market inefficiency is primarily driven by supply-side barriers such as the last-mile problem or regulation, comparison websites are less likely to have an impact.

This project will assess whether comparison websites, and comparison shopping more generally, have the potential to impact the demand and supply sides of the remittance industry. ${ }^{2}$ In so doing, we will seek to describe consumer, firm, and industry characteristics that may moderate such impacts. Our research questions are as follows:

\section{Demand-side}

(a) Do comparison websites impact consumer outcomes? For example, i) consideration sets and search, i.e., the firms that are considered and their associated attributes such as price components (i.e., fee versus exchange rate) and trustworthiness; ii) ultimate choice of firm, amount sent, and prices paid; and iii) response to price changes, including switching between firms.

(b) Are the above impacts moderated by i) sender or recipient characteristics such as financial literacy and inclusion (e.g., ability to access electronic funds or mobile money) or other forms of comparison shopping (e.g., via phone or in person); ii)

\footnotetext{
${ }^{1}$ See for example http://bit.ly/2zZIXJZ (accessed December 18, 2020).

${ }^{2}$ This project is different from Nakasone et al. (2020), which uses eye-tracking data to assess whether migrants visually pay attention to information on a comparison site when searching across firms.
} 
firm characteristics such as ease of sending or receiving the funds (e.g., online or in person and density/network of store locations); and iii) industry characteristics such as regulatory barriers or informal channels for sending money?

\section{Supply-side}

(a) Do comparison websites impact firm outcomes? For example, i) the marginal cost of providing remittances services and thus, profit margins and ii) firms' market power, which may be affected by consumer characteristics such as financial literacy and inclusion and the firm's coverage network on the sender and recipient ends.

(b) Are the above impacts moderated by i) industry characteristics such as regulatory barriers (e.g., anti-fraud and money-laundering) or ii) other types of market inefficiencies such as infrastructural barriers (e.g., last-mile problem)?

3. Welfare. What are the potential welfare effects of i) comparison sites and shopping; ii) information interventions; and (iii) other related policy interventions?

Even though we present them separately for tractability purposes, the demand and supply sides of the market are intertwined. Suppose a consumer wants to send money from point A to point $\mathrm{B}$ in the formal market and only cares that the funds reach the recipient. Even though several firms may service corridor A-B, the consumer will choose the firm that is most likely to complete the transaction. So, the consumer's choice and firm's market power will be impacted by characteristics such as the firm's trustworthiness and ability to deliver the funds as well as recipient characteristics such as financial inclusion, e.g., whether or not the recipient can receive funds electronically. These issues will further be impacted by industry and corridor characteristics such as regulatory, ease-of-doing-business, and last-mile barriers as well as informal means for sending money.

Given the above and the fact that our ultimate goal is to assess the potential welfare impacts of policy interventions, this project will have three stages. The first stage, which is laid out in this version of the pre-analysis plan (PAP), will exploit existing data to do a first pass on the demand- and supply-side questions. The second stage, which will be pre-registed as an updated version of this PAP, will collect primary data and additional secondary data to pin down causal factors. The final stage will incorporate findings from the first two stages to assess potential welfare impacts through simulations. Stated differently, each stage will inform the design of the next.

Our findings will contribute to the intersection of at least three literatures. First, the impact of information on search and consideration sets (e.g., Stigler, 1961; Bakos, 1997; Brown and Goolsbee, 2002; Mehta et al., 2003; Baye et al., 2004; Jensen, 2007; Ellison and Ellison, 2009; De Los Santos et al., 2012; Honka, 2014; Scott Morton et al., 2015; Choi et al., 2018; Bai et al., 2020). Second, the potential drivers of remittance sending and prices (e.g., Beck and Martinez Peria, 2011; Chin et al., 2011; Yang, 2011; Kosse and Vermeulen, 2014; Ambler et al., 2014; Ashraf et al., 2015; Torero and Viceisza, 2015; Nakasone et al., 2020). Third, the impact of training on financial decision-making and literacy (e.g., Gibson et al., 2012; Kaiser et al., 2020). From a methodological standpoint, our work also relates to a growing literature that presents descriptive statistics alongside structural estimates, particularly in development (see for example Andrews et al., 2020, and the references within). 


\section{Empirical strategy and data}

Since the first stage of this project is exploratory, this section is based on the following principles. First, the empirical strategy is discussed at a high level. I.e., the analysis is likely to expand as we i) gain additional insights from the data and/or ii) get access to new data sources. Second, the analysis will primarily be based on descriptive and summary statistics as well as correlational regressions.

In what follows, let:

1. $Y$ be an outcome variable of interest, e.g., consumer search and choices or firm services and prices.

2. $X$ be the main independent variable of interest such as awareness, use, and presence of comparison websites or comparison shopping more generally.

3. $Z$ be other control variables of interest such as consumer, recipient, firm, corridor, or industry characteristics. While some $Z$ variables may not exhibit variation at a level where we could include them in a regression, they will still be described to get a sense of how the remittance industry compares to industries where comparison sites seem to have had an impact, e.g., insurance and travel.

In addition to summarizing and describing $Y, X$, and $Z$, our main strategy will rely on regressions of the following form:

$$
Y=\beta_{0}+\beta_{1} X+\beta_{2} Z+\epsilon
$$

and

$$
Y=\beta_{0}+\beta_{1} X+\beta_{2} Z+\beta_{3} X * Z+\varepsilon
$$

The feasibility of these regressions and the level at which they vary (e.g., individual, corridor, type of service, or over time) will depend on the data source in question. The following sections discuss some details dataset by dataset. The information in parenthesis can typically be interpreted as follows: 1) A number is the corresponding survey question; 2) "E" means that the data/variables come from an experiment (e.g., a treatment condition); and 3) otherwise, it references a variable in the respective dataset.

\subsection{Remittance Prices Worldwide (RPW)}

Details about RPW can be accessed at https://bit.ly/3daRdIX. Possible variables include:

1. $Y$

(a) Fee of sending US\$200 from country $i$ to country $j$ (cc1 fee)

(b) Exchange rate margin versus interbank exchange rate of sending US\$200 from country $i$ to country $j$ (cc1 fx margin)

(c) Total Fee of sending US\$200 from country $i$ to country $j$ (cc1 total cost \%) 
(d) Fee of sending US\$500 from country $i$ to country $j$ (cc2 fee)

(e) Exchange rate margin versus interbank exchange rate of sending US\$500 from country $i$ to country $j$ (cc2 fx margin)

(f) Total Fee of sending US\$500 from country $i$ to country $j$ (cc2 total cost \%)

2. $X$

(a) Type of firm (Bank, money-transfer operator/MTO, Non-bank FI, Post-office) (firm type)

(b) Payment instrument option such as cash, transfer, mobile money, etc. (payment instrument)

(c) Pickup method option such as cash, home delivery, etc. (pickup method)

(d) Time for the money to be available for the receiver (speed actual)

(e) Whether the firm has a low, medium or high level of coverage in the recipient country (Receiving network coverage)

3. $Z$

(a) Characteristics of the source country and the destination country. RPW includes region and income level, but this information could be complemented by other sources with country level data.

\subsection{Ambler et al. (2015)}

Details about Ambler et al. (2015)'s study can be accessed at http://bit.ly/3dewkwi. Possible variables include:

1. $Y$

(a) Migrant $i$ average 'regular' remittances to target household (E3) 3

(b) Migrant $i$ 's frequency of 'regular' remittances to target household (E2)

(c) Migrant $i$ 's additional (not regular) remittances to target household (E4)

(d) Migrant $i$ 's average 'regular' remittances to other households (E7)

(e) Migrant $i$ 's frequency of additional remittances to other households (E6)

(f) Migrant $i$ 's additional (not regular) remittances to other households (E8)

2. $X$

(a) The treatments. Also see $Z$ variables.

3. $Z$

(a) Migrant $i$ 's characteristics such as gender (B1), age (B2), marital status (B3), literacy (B4), education level (B5), children living in El Salvador (B9), number and relation to close relatives living in El Salvador (B12).

\footnotetext{
3The authors define "regular" remittances as those sent on a regular basis to help pay for recurring, day-to-day expenses. Target household refers to the household where the selected recipient (student) lives.
} 


\subsection{Ashraf et al. (2015)}

Details about Ashraf et al. (2015)'s study can be accessed at https://bit.ly/3pVY6kh. Possible variables include:

1. $Y$

(a) Monthly remittances sent by migrant $i$ post-treatment (USremit_p2h)

(b) An aggregation of the balance in savings accounts where only the recipient can withdraw, from 22 months before treatment to 56 months after (savo_22 up to savo56)

2. $X$

(a) Account offer for someone in El Salvador (treatment group 1, visita=1)

3. $Z$

(a) Migrant $i$ 's characteristics such as gender (USfemale), whether $i$ is a US citizen or not (US_nat), age (US_age), relationship to remittance recipient (parent/child/spouse/other), years in the United States (US_years), correct answer to financial literacy questions on compound interest, inflation and mutual fund (finlitq1, finlitq2, finlitq3).

\subsection{Nakasone et al. (2020)}

Details about Nakasone et al. (2020)'s study can be accessed at http://bit.ly/3d3c4M3. Possible variables include:

1. $Y$

(a) The firm $j$ that individual $i$ chooses (103 or E)

(b) The amount that individual $i$ sends via firm $j$ (103)

(c) The price that individual $i$ pays at firm $j$ for sending a certain amount, possibly as a percent (104)

(d) Whether the firm $j$ that individual $i$ chooses is the same across the pre-survey and the experiment (103 and E)

(e) The time that individual $i$ spends prior to making a final choice of firm $j$ (E)

2. $X$

(a) Whether individual $i$ is aware of and/or uses comparison sites (89-95)

(b) Whether individual $i$ comparison-shops generally or in other ways, e.g., via phone or in person $(85,87-88)$

(c) Whether individual $i$ is exposed to additional information about firm attributes, e.g., trustworthiness and/or delivery speed (E) 
3. $Z$

(a) Consumer characteristics such as financial literacy $(99,117)$, financial inclusion $(8-9,96)$, behavioral characteristics such as trust and risk-taking $(113,80)$, preferences for remittance attributes (86) and remittance spending (107), and other demographics such as age (11), gender (10), education (73), household size (74), and marital status (75).

(b) Recipient characteristics such as financial inclusion (97) and ease of accessing funds, e.g., rural or urban location of the recipient (102).

(c) Corridor characteristics such as the country $c$ that individual $i$ sends to (13).

\subsection{Lee et al. (2021)}

Details about Lee et al. (2021)'s study can be accessed at http://bit.ly/2OsKNKI. Possible variables include:

1. $Y$

(a) Migrant $i$ 's total number of remittances (num_remittances)

(b) Migrant $i$ 's total number of remittances sent via mobile (mobile_money_num)

(c) Migrant $i$ 's annual value of remittances (total_remittances)

(d) Migrant $i$ 's annual value of mobile money remittances (total_bKash_remittances)

2. $X$

(a) bKash Treatment (treatment)

3. $Z$

(a) Migrant i's characteristics such as age, gender, mobile phone ownership, bank account ownership, formal employment, and completion of primary school.

(b) Migrant $i$ 's receiving household characteristics such as household size, number of children, and subdistrict as well as household head's age, gender, and education.

\subsection{Other analyses}

As feasible, we will also conduct other analysis. For example:

1. We will try to get a further sense of regulatory and last-mile barriers by using textual analysis (e.g., along the lines of Calomiris et al., 2020) and replicating the analysis of Beck and Martinez Peria (2011). Our main sources will include 1) financial reports of MTOs (e.g., Western Union and MoneyGram), 2) regulatory/policy documents and reports (e.g., Bank of International Settlements/BIS, Consumer Financial Protection Bureau, International Monetary Fund, World Bank, and US Treasury), 3) newsletters of associations and international organizations (e.g., FXC Intelligence, International 
Association of Money Transfer Networks, Money Services Business Association, and Financing Facility for Remittances), and 4) datasets such as the World Bank's Global Payment Systems Survey.

2. We will document a list of remittance service providers and comparison websites for corridors of interest based on 1) established lists (e.g., RPW), 2) web searches, including blogs (e.g., Platinum Network and International Money Transfer Conferences), and 3) the above newsletters and sources. We will also seek to obtain web traffic statistics for MTOs that have a digital presence and comparison sites through sources such as Google analytics and Alexa.

3. We will assess likely generalizability of our findings by comparing certain characteristics (including informality where feasible) across corridors. This will be based on the above sources, in particular RPW, as well as prior literature (e.g., Kosse and Vermeulen, 2014. and the references within).

\section{Timeline and implementation}

The project will progress according to the following approximate timeline (some of which will depend on the evolution of the COVID-19 pandemic and data access):

- Spring-Summer 2021: Stage 1 data analysis + file revised PAP.

- Fall 2021-Fall 2022: Stage 2 data collection and analysis + file revised PAP.

- Spring 2023-Spring 2024: Stage 3 welfare analysis.

\section{Acknowledgments}

We thank audiences at Stanford University (Eddie Lunch and Hoover) for helpful comments. We are particularly grateful to the National Science Foundation for financial support through Excellence in Research award number 1832144. Viceisza is also thankful to the Hoover Institution at Stanford University where he visited as a W. Glenn Campbell and Rita Ricardo-Campbell National Fellow and the John Stauffer National Fellow during the 2020-21 academic year.

\section{References}

Adams, Jr., R. H. (1998). Remittances, investment, and rural asset accumulation in Pakistan. Economic Development and Cultural Change 47(1), 155-173.

Alcaraz, C., D. Chiquiar, and A. Salcedo (2012). Remittances, schooling, and child labor in Mexico. Journal of Development Economics 97(1), 156 - 165. 
Ambler, K., D. Aycinena, and D. Yang (2014, September). Remittance responses to temporary discounts: A field experiment among Central American migrants. Working Paper 20522, National Bureau of Economic Research.

Ambler, K., D. Aycinena, and D. Yang (2015, April). Channeling remittances to education: A field experiment among migrants from El Salvador. American Economic Journal: Applied Economics 7(2), 207-32.

Amuedo-Dorantes, C. and S. Pozo (2011, March). New evidence on the role of remittances on healthcare expenditures by Mexican households. Review of Economics of the Household 9(1), 69-98.

Andrews, I., M. Gentzkow, and J. M. Shapiro (2020). On the informativeness of descriptive statistics for structural estimates. Econometrica 88(6), 2231-2258.

Ashraf, N., D. Aycinena, C. Martínez A., and D. Yang (2015). Savings in transnational households: A field experiment among migrants from El Salvador. The Review of Economics and Statistics 97(2), 332-351.

Bai, J., M. Chen, J. Liu, and D. Y. Xu (2020, November). Search and information frictions on global e-commerce platforms: Evidence from AliExpress. Working Paper 28100, National Bureau of Economic Research.

Bakos, J. Y. (1997). Reducing buyer search costs: Implications for electronic marketplaces. Management Science 43(12), 1676-1692.

Baye, M. R., J. Morgan, and P. Scholten (2004). Price dispersion in the small and in the large: Evidence from an internet price comparison site. The Journal of Industrial Economics 52(4), 463-496.

Beck, T. and M. S. Martinez Peria (2011, 05). What Explains the Price of Remittances? An Examination Across 119 Country Corridors. The World Bank Economic Review 25(1), $105-131$.

Brown, J. R. and A. Goolsbee (2002). Does the internet make markets more competitive? evidence from the life insurance industry. Journal of Political Economy 110(3), 481-507.

Brown, R. P. (1994). Migrants' remittances, savings, and investment in the South Pacific. International Labour Review 133(3), 347-367.

Calomiris, C. W., H. Mamaysky, and R. Yang (2020, March). Measuring the cost of regulation: A text-based approach. Working Paper 26856, National Bureau of Economic Research.

Chin, A., L. Karkoviata, and N. Wilcox (2011). Impact of bank accounts on migrant savings and remittances: Evidence from a field experiment.

Choi, M., A. Y. Dai, and K. Kim (2018). Consumer search and price competition. Econometrica 86(4), 1257-1281. 
De Los Santos, B., A. Horta, csu, and M. R. Wildenbeest (2012, May). Testing models of consumer search using data on web browsing and purchasing behavior. American Economic Review 102(6), 2955-80.

Edwards, A. C. and M. Ureta (2003). International migration, remittances, and schooling: evidence from El Salvador. Journal of Development Economics 72(2), 429-461.

Ellison, G. and S. F. Ellison (2009). Search, obfuscation, and price elasticities on the internet. Econometrica $77(2), 427-452$.

Finkelstein Shapiro, A. and F. S. Mandelman (2016). Remittances, entrepreneurship, and employment dynamics over the business cycle. Journal of International Economics 103, $184-199$.

Gibson, J., D. McKenzie, and B. Zia $(2012,12)$. The Impact of Financial Literacy Training for Migrants. The World Bank Economic Review 28(1), 130-161.

Gyimah-Brempong, K. and E. Asiedu (2015). Remittances and investment in education: Evidence from Ghana. The Journal of International Trade 83 Economic Development 24(2), $173-200$.

Honka, E. (2014). Quantifying search and switching costs in the us auto insurance industry. The RAND Journal of Economics 45(4), 847-884.

Jensen, R. (2007, 08). The Digital Provide: Information (Technology), Market Performance, and Welfare in the South Indian Fisheries Sector. The Quarterly Journal of Economics 122(3), 879-924.

Kaiser, T., A. Lusardi, L. Menkhoff, and C. J. Urban (2020, April). Financial education affects financial knowledge and downstream behaviors. Working Paper 27057, National Bureau of Economic Research.

Kosse, A. and R. Vermeulen (2014). Migrants' choice of remittance channel: Do general payment habits play a role? World Development 62, $213-227$.

Lee, J. N., J. Morduch, S. Ravindran, A. Shonchoy, and H. Zaman (2021, January). Poverty and migration in the digital age: Experimental evidence on mobile banking in Bangladesh. American Economic Journal: Applied Economics 13(1), 38-71.

Luco, F. (2019, May). Who benefits from information disclosure? the case of retail gasoline. American Economic Journal: Microeconomics 11(2), 277-305.

Mehta, N., S. Rajiv, and K. Srinivasan (2003). Price uncertainty and consumer search: A structural model of consideration set formation. Marketing Science 22(1), 58-84.

Nakasone, E., M. Torero, and A. Viceisza (2020, September 8). Neuroeconomics for development: Eye-tracking to understand migrant remittances. AEA, RCT Registry. 
Nishida, M. and M. Remer (2018). The determinants and consequences of search cost heterogeneity: Evidence from local gasoline markets. Journal of Marketing Research 55(3), $305-320$.

Osili, U. O. (2007). Remittances and savings from international migration: Theory and evidence using a matched sample. Journal of Development Economics 83(2), 446 - 465. Papers from a Symposium: The Social Dimensions of Microeconomic Behaviour in LowIncome Communities.

Riley, E. (2018). Mobile money and risk sharing against village shocks. Journal of Development Economics 135, 43 - 58.

Scott Morton, F., R. C. Romaine, and S. Graf (2015). Benefits of preserving consumers? ability to compare airline fares. Project report, Charles River Associates: Boston, MA.

Stigler, G. J. (1961). The economics of information. Journal of Political Economy 69(3), $213-225$.

Torero, M. and A. Viceisza (2015). To remit, or not to remit: that is the question. A remittance field experiment. Journal of Economic Behavior 85 Organization 112, 221 236.

Woodward, S. E. and R. E. Hall (2012, December). Diagnosing consumer confusion and sub-optimal shopping effort: Theory and mortgage-market evidence. American Economic Review 102(7), 3249-76.

Yang, D. (2011). Migrant remittances. Journal of Economic Perspectives 25(3), 129-52. 